\title{
Variation in species composition and infection rates of Anopheles mosquitoes at different altitudinal transects, and the risk of malaria in the highland of Dirashe Woreda, south Ethiopia
}

\author{
Taye Yohannes Daygena ${ }^{1,2}$, Fekadu Massebo ${ }^{1 *}$ and Bernt Lindtjørn ${ }^{3}$
}

\begin{abstract}
Background: The transmission of malaria is heterogeneous, and varies due to altitude. The information on whether the transmission of malaria is indigenous or imported to highland areas is scarce. Therefore, this study aimed to assess the species composition and infection rates of Anopheles at different altitudinal transects, and the risk of malaria if any in the highland of Dirashe Woreda, South Ethiopia.

Methods: This study was conducted in Gato (low altitude; average elevation of 1273 m), Onota (mid-altitude; average elevation of $1707 \mathrm{~m}$ ) and Layignaw-Arguba (high altitude; average elevation of $2337 \mathrm{~m}$ ) from August 2015 to April 2016. Anopheles mosquitoes were sampled using Centers for Disease Control and Prevention (CDC) light traps from thirty houses (ten houses from each village). The circum-sporozoite proteins (CSPs) rate and entomological inoculation rate (EIR) of Anopheles mosquitoes were estimated. For the epidemiological survey, malaria cases were collected from laboratory registration books of selected health facilities from (August 2015-April 2016). A cross-sectional survey was done to collect data on malaria vector control activities in each village (August-September 2015).

Results: One thousand two hundred sixty-eight Anopheles mosquitoes comprising Anopheles arabiensis, An. demeilloni, An. cinereus, An. pharoensis, An. funestus-group, An. pretoriensis, An. christyi, An. ardensis and An. tenebrosus were identified in the study area. Anopheles arabiensis was the dominant species in Gato, whereas An. demeilloni was the dominant species in Layignaw-Arguba. Five mosquitoes, three An. arabiensis from Gato and two An. demeilloni from Layignaw-Arguba, were positive for Plasmodium falciparum CSPs. Plasmodium falciparum CSP rate was 0.4\% (95\% Cl: 0. 08-1.15) for An. arabiensis in Gato, and it was $0.64 \%$ (95\% Cl: 0.08-2.3) for An. demeilloni from Layignaw-Arguba. The P. falciparum EIR of An. arabiensis was 8.6 (95\% Cl: 2.4-33.4) infectious bites/person/nine-months in Gato. Plasmodium falciparum parasite was dominant in Gato (88\%) and Onota (57.5\%), whereas in Layignaw-Arguba P. vivax (59.4\%) occurred most frequently. Increased malaria cases were observed in children age $5-14$ years in Gato $(P<0.05)$, whereas in Onota and Layignaw-Arguba there was no statistically significant difference in malaria cases among the age groups. Households owning at least one long lasting insecticidal net were $92.7 \%$ in the study area, and $77.6 \%$ slept under the net during the preceding night of the survey. About $64.4 \%$ of the households in Gato were protected by the indoor residual spray. However, the spraying was done when the density of local malaria vectors was low.

\footnotetext{
* Correspondence: fekadu.massebo@amu.edu.et

'Department of Biology, Arba Minch University, Arba Minch, Ethiopia

Full list of author information is available at the end of the article
} 
(Continued from previous page)

Conclusion: Incrimination of Plasmodium CSP positive Anopheles species and the presence of malaria in children under five years in high altitude Layignaw-Arguba may justify the existence of indigenous malaria transmission and the need for effective malaria control. Further investigation and confirmation using more sensitive molecular techniques are however needed to consider An. demeilloni as a proven vector of malaria in Ethiopia.

Keywords: Altitudinal variation, Anopheles arabiensis, Anopheles demeilloni, Dirashe Woreda

\section{Background}

Malaria is a major public health problem of the world with the highest disease burden in sub-Saharan Africa [1]. In Ethiopia, malaria is the leading vector-borne disease and was among the ten leading causes of sickness and deaths in children less than five years of age. The epidemiological pattern of malaria is mostly unstable and seasonal, but its intensity differs from place to place due to altitudinal and climatic variations [2].

The areas with altitude $2000 \mathrm{~m}$ above sea level (masl) have been considered as malaria-free, but currently areas above 2400 masl experience local malaria transmission $[3,4]$. The expansion of malaria transmission to highland areas has been influenced by the change in climatic conditions [5]. The increasing temperature may shorten the developmental time of the malaria parasite within the mosquito vector and hasten the development of immature stages of Anopheles mosquitoes [6, 7]. Moreover, the population in areas with unstable malaria transmission is non-immune and experiences malaria epidemics [8] including the highlands of Ethiopia [9]. Travelling from the highlands to the lowlands for daily activities increases the risk of malaria infection in highland residents [10]. Therefore, the geographical expansion of malaria to the highlands could be a serious public health concern because most of the population lives in the highlands of the country.

In Ethiopia, highlands ranging from an altitude of 1500-2500 m experienced a huge malaria epidemic in 1958 [11]. Also, Anopheles species such as An. arabiensis (the principal malaria vector), An. christyi, An. demeilloni and $A n$. coustani have been documented in highland areas [3, 12, 13]. Gone et al. [13] have reported Anopheles species from lowland and highland of Dirashe. Anopheles arabiensis, An. funestus, An. demeilloni and An. pharoensis were documented in low altitude, $A n$. demeilloni and $A n$. cinereus at mid altitude, and $A n$. demeilloni from the high altitude of Dirashe. However, no adequate entomological and parasitological studies were conducted in the area to determine whether the transmission of malaria is indigenous or imported to the highlands. In the previous study conducted by Gone et al. [13], few mosquitoes were collected, and none of them was positive for Plasmodium parasites, and therefore, the existing evidence may not be sufficient to conclude the presence of local malaria transmission in the highlands of the study area. Hence, the present study aimed to investigate variation in species composition, sporozoite infection rates of Anopheles mosquitoes, and estimate the risk of malaria at different altitudinal transects of Dirashe Woreda in south Ethiopia using circum-sporozoite proteins (CSPs), entomological inoculation rates (EIR), and malaria parasite prevalence.

\section{Methods \\ Study area}

This study was conducted in three kebeles (villages) at different altitudinal transects in Dirashe Woreda (district) south Ethiopia. These were Gato (low altitude), Onota (middle altitude) and Layignaw-Arguba (high altitude) (Fig. 1). The altitude of Gato is between 1248 and 1298 masl. The other village Onota is $9 \mathrm{~km}$ away from Gato and is located at an altitude between 1573 and 1842 masl. Layignaw-Arguba is a highland village with altitude ranging from 2060 to 2614 masl. The soil is fertile, and farming is the main mode of living for the local people. The main crops are maize, sorghum and teff (Eragrostis tef). Gato is one of the productive villages of the area using irrigation water from the River Yanda which crosses the village from West to East. Onota has varying topography with steep slopes and some plateau in the middle. Surface water is scarce in Onota. On the other hand, Layignaw-Arguba has several swampy areas, many springs, and ponds with a variable topography, vegetation cover and land use.

The annual rainfall ranges between 600 and $1600 \mathrm{~mm}$, and the annual temperature ranges between 15.1 and to $27.5{ }^{\circ} \mathrm{C}$. There is a bimodal rainy season with the long rainy months from March to June and the short rainy months from September to October (unpublished district agricultural office data, 2014). Health services are provided by one primary hospital, four health centres, fourteen health posts and thirty-two private health facilities. The total population of the district is estimated to be 130,276 (63,785 males and 66,491 females). The population of Gato is 12,327 . Onota has a population of 6381, whereas the population of Layignaw-Arguba is 6569. The total number of households in the three villages is 5159; Gato has 2516, Onota 1302 and 


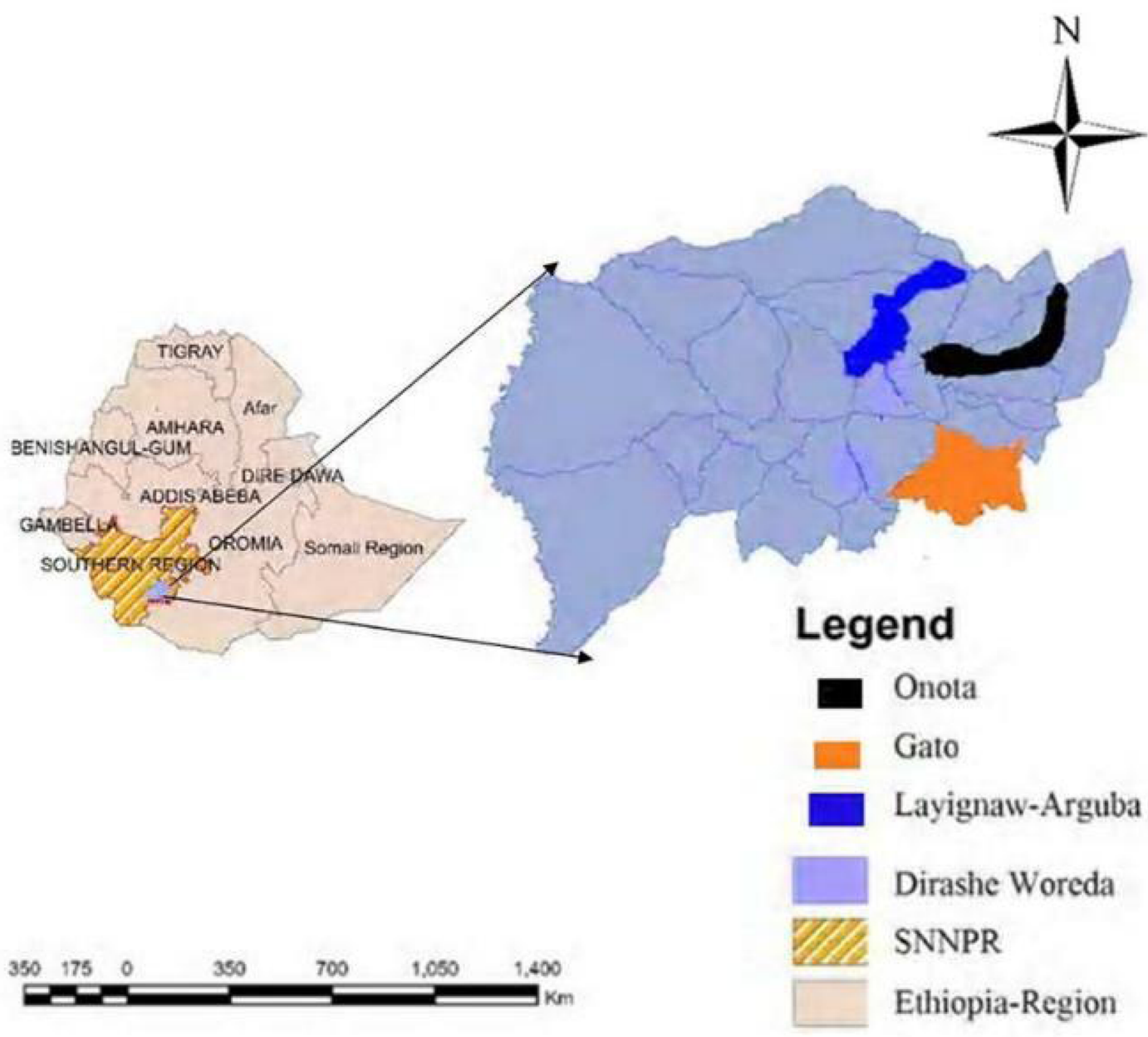

Fig. 1 Map of the study areas in Dirashe Woreda, south Ethiopia

Layignaw-Arguba 1341 (unpublished district health office data of 2015).

\section{Entomological study designs}

A longitudinal entomological study was conducted from August 2015 to April 2016. Adult Anopheles mosquitoes were collected twice a month using Centers for Disease Control and Prevention (CDC) light traps. Ten houses were selected randomly from each of the three villages. After obtaining consent from the head of the households, CDC light traps were installed in the sleeping places of the selected houses (from 18:00 to 06:00 h) at about $1.5 \mathrm{~m}$ above the floor near the foot end of the person sleeping under the insecticide untreated bednet [14]. A total of $60 \mathrm{CDC}$ light trap-nights per month were conducted. The same households were surveyed throughout the study. The live mosquitoes were sucked by aspirator from collection bags and killed by freezing. Female Anopheles mosquitoes were then identified morphologically to species under a stereomicroscope using a morphological identification key [15]. The abdominal status of female Anopheles mosquitoes was determined under the microscope into unfed, freshly-fed, half-gravid and gravid. Finally, each female Anopheles mosquito was preserved individually in Eppendorf tube containing silica gel for detection of CSPs using enzyme-linked immunosorbent assay (ELISA) [16].

\section{Processing female Anopheles mosquitoes for CSPs detection}

The two dominant species, $A n$. gambiae (presumably $A n$. arabiensis) and An. demeilloni were analysed for CSP detection using ELISA [16]. The head and thorax of dried females were separated carefully from the abdomen and tested for P. falciparum and P. vivax_210 CSPs in Arba Minch University Medical Entomology Laboratory.

\section{Retrospective malaria data collection}

The total number of outpatient attendant cases suspected of having malaria was confirmed by microscopic 
or rapid diagnostic test (RDT) in the selected health centres and health posts. The selection of the health facilities was not random but was based on where most people go for health care. Two health centres and four health posts were used for the survey. Malaria positive cases were categorised using standard age groups for malaria as $<1$ year, $1-4$ years, $5-14$ years and $15+$. All microscopic or RDT positive malaria cases were identified and classified into P. falciparum, P. vivax and mixed infections.

\section{Survey of vector control interventions}

The sample size required for a cross-sectional survey to assess the vector control intervention coverage and use rate was determined using Epi Info ${ }^{\text {тw }}$ (http://www.cdc.gov/ epiinfo). The total number of households in the three villages was 5139. To determine the sample size of the survey, $50 \%$ malaria control intervention coverage, the margin of error of $4 \%$ and $95 \%$ confidence level $(\alpha=5 \%)$ was considered. Therefore, the total sample size calculated was 538 households. Thus, the sample size of each village was calculated proportionally based on their total number of households. Hence, the number of households needed for the survey in Gato was 262, and it was 136 in Onota and 140 in Layignaw-Arguba.

The households included in the study were selected by systematic random sampling technique. The list of households of the three villages was used as sampling frame with the assumption of similar access to vector control interventions. The first household was selected randomly by lottery method, and every $\mathrm{K}^{\text {th }}$ household was included in the study. $\mathrm{K}$ was calculated by the formula

$$
\mathrm{K}=\frac{N}{n}
$$

where $\mathrm{K}$ is the gap between every household, $\mathrm{N}$ is the total number of households in the study village, and $\mathrm{n}$ is the sample size calculated. Since the sample was allocated proportionally, $\mathrm{K}$ was the same for each of the study villages.

House to house surveys were conducted by trained data collectors using structured and pre-tested questionnaires. After obtaining consent, the data collector interviewed the household head. The information collected includes malaria prevention and control strategies such as having bednets, the number of bednets, registering if anyone slept under the bednet the night before the survey and insecticide spray status in the last 12 months. The household occupants who lived in the study areas for more than six months were included in the study. If the household's occupants refused to participate, the household next to it was included in the survey.

\section{Outcome variables}

The primary outcome variables were Anopheles mosquito species composition, sporozoite rates and EIR along with the altitudinal transects. Other primary outcomes include the number of malaria cases and Plasmodium species at different altitudinal gradients. The secondary outcome variables were the number of households owning LLINs or sprayed, and the number of households using the LLINs the night before the survey in the study villages.

\section{Data analysis}

Data were entered and analysed by using $\mathrm{IBM}^{\circ} \mathrm{SPSS}^{\circ}$ Statistics version 20 (Armonk, New York: IBM Corporation). Analysis of variance was used to compare the density of Anopheles mosquitoes and malaria cases at different altitudinal transects of the district. The sporozoite rate was determined for CDC light trap catches. For CDC based EIR, the conversion factor of 1.91 was used [17]. Thus, the standard EIR was calculated as 1.91 multiplied by (number of sporozoite positive ELISAs/ number of mosquitoes tested) $\times$ (number of mosquitoes collected by CDC/number of CDC catches) [17]. The alternative method was also used to calculate the 95\% confidence interval of EIR. The number of malaria cases was estimated as the number of cases per total number of persons suspected and tested for malaria. The difference in bednet use rates in different altitudinal transects and malaria cases in different age groups were compared using the Chi-square test.

\section{Results}

\section{Anopheles species composition}

A total of 1268 adult female Anopheles mosquitoes comprising nine species were collected. Of these, seven species were found in Gato, three species in Onota and four species in Layignaw-Arguba. Anopheles gambiae (s.l.) (An. arabiensis) was the predominant species (59.5\%; 755/1268), followed by An. demeilloni (27.4\%; 347/1268). The other species were An. cinereus, An. pharoensis, $A n$. funestus group, An. pretoriensis, An. christyi, An. ardensis and An. tenebrosus (Table 1).

The density of Anopheles mosquitoes at different altitudinal transects of the district varied significantly $(F=53.7, d f=2, P<0.001)$. Anopheles arabiensis was the most common species $(91.1 \%$; 754/828) in Gato while $A n$. demeilloni was the most prevalent species in Onota (59.4\%; 19/32), and in Layignaw-Arguba (76.2\%; 311/408). No An. arabiensis were collected in LayignawArguba and this species was among the rare species in Onota. Anopheles christyi was collected in LayignawArguba only.

The abundance of mosquitoes showed seasonal variations (Fig. 2). The monthly density of Anopheles 
Table 1 Anopheles species composition of indoor adult collection using CDC light traps in three study villages of Dirashe Woreda, south Ethiopia (August 2015-April 2016)

\begin{tabular}{lllll}
\hline Anopheles species & \multicolumn{3}{l}{ Study villages } \\
\cline { 2 - 5 } & Gato & $\begin{array}{l}\text { Onota } \\
n(\%)\end{array}$ & $\begin{array}{l}\text { Layignaw-Arguba } \\
n(\%)\end{array}$ & Total (\%) \\
\hline An. arabiensis & $754(91.1)$ & $1(3.1)$ & $0(0)$ & $755(59.5)$ \\
An. demeilloni & $17(2.1)$ & $19(59.4)$ & $311(76.2)$ & $347(27.4)$ \\
An. cinereus & $0(0)$ & $12(37.5)$ & $90(22.1)$ & $102(8.0)$ \\
An. funestus group & $22(2.7)$ & $0(0)$ & $0(0)$ & $22(1.7)$ \\
An. pharoensis & $22(2.7)$ & $0(0)$ & $0(0)$ & $22(1.7)$ \\
An. christyi & $0(0)$ & $0(0)$ & $6(1.5)$ & $6(0.5)$ \\
An. pretoriensis & $7(0.8)$ & $0(0)$ & $1(0.2)$ & $8(0.6)$ \\
An. ardensis & $3(0.4)$ & $0(0)$ & $0(0)$ & $3(0.2)$ \\
An. tenebrosus & $3(0.4)$ & $0(0)$ & $0(0)$ & $3(0.2)$ \\
Total & 828 & 32 & 408 & 1268 \\
\hline
\end{tabular}

mosquitoes varied significantly $(F=10.7, d f=8$, $P<0.001)$. Anopheles mosquitoes were collected mainly from November to January, and in April in Gato, from February to April in Onota, and from January to April in Layignaw-Arguba.

\section{Abdominal status of female Anopheles mosquitoes}

Of 1268 adult female Anopheles mosquitoes collected by CDC light traps, the majority $(56.9 \%$; 721) were unfed, and $467(36.8 \%)$ were freshly-fed. Only a small proportion of Anopheles mosquitoes were half-gravid and gravid. In Gato, of 828 collected adult Anopheles females, 499 (60.3\%) were unfed and $265(32.0 \%)$ were freshly-fed. In Onota $71.9 \%$ (23 of the 32) were unfed. The trend was similar in Layignaw-Arguba where many female Anopheles were unfed $(48.8 \% ; 199)$, and freshlyfed $\left(47.8 \%\right.$; 195) $\left(\chi^{2}=354.5, d f=3, P<0.001\right)$ (Table 2).

\section{CSPs rates of Anopheles mosquitoes}

A total of 1102 CDC light traps collected An. arabiensis and An. demeilloni were tested for Plasmodium CSPs using ELISA (Table 3). Five Anopheles mosquitoes were positive for Plasmodium CSPs (three An. arabiensis in Gato and two An. demeilloni in Layignaw-Arguba). The overall CSP rate of Anopheles mosquitoes for P. falciparum was $0.45 \%$ (95\% CI: $0.06-1.1 \%$ ) (5 of 1102). Plasmodium falciparum CSP rate of An. arabiensis from Gato was $0.4 \%$ (95\% CI: $0.08-1.15 \%$ ) (3 of the 754 ) but, no $A n$. arabiensis was positive for $P$. vivax CSP. In Onota, one An. arabiensis and 19 An. demeilloni were tested for CSP, and all were negative. In LayignawArguba, two An demeilloni were positive for P. falciparum CSP. Hence, the P. falciparum CSP rate of An. demeilloni was $0.64 \%$ (95\% CI: $0.08-2.3 \%$ ) (2 of the 311 ), but no P. vivax positive An. demeilloni were detected.

\section{EIR of Anopheles mosquitoes}

The overall estimated P. falciparum EIR of An. arabiensis was 8.6 (95\% CI: 1.7-24.8) infectious bites per person (ib/p)/nine months (Table 4). The estimated monthly $P$. falciparum EIR of An. arabiensis was highest in January 2016 (5.9; 95\% CI: 0.7-18.7), when the density of $A n$. arabiensis was also higher compared to the other months. The P. falciparum EIR in October was 2.9 (95\% CI: 0.07-14.7) for An. arabiensis. The EIR was not estimated for An. demeilloni because the species is not so far incriminated as a malaria vector, and no conversion factor was established to estimate the human biting rate from CDC light traps.

\section{Malaria cases and Plasmodium species at different altitudinal transects}

Of 2240 microscopy or RDT tests from malaria suspected outpatients, 405 (18.1\%) were positive for $P$. falciparum, $P$. vivax or mixed infection. Plasmodium falciparum accounted for 34.3\% (139 of the 405), whereas $P$. vivax accounted $18.3 \%$ (74 of the 405). Mixed infection of $P$. falciparum and $P$. vivax was predominant (47.4\%; 192 of the 405). More mixed infections were documented by RDT test $(66.1 \% ; 127 / 333)$ in the lowland Gato $\left(x^{2}=63.68, d f=1, P<0.001\right)$. Plasmodium falciparum (including the mixed infection) was the predominant species $(88 \% ; 293 / 333)$ in Gato. In Onota $P$. falciparum was also dominant species $(57.5 \%$; 23/40), whereas more $P$. vivax $(59.4 \% ; 19$ of the 32$)$ cases were reported from Layignaw-Arguba. More malaria cases were observed in Gato than in Onota and LayugnawArguba $\left(\chi^{2}=102.2, d f=2, P<0.001\right)$ but, the difference was not statistically significant between Onota and Layignaw-Arguba $\left(\chi^{2}=16.85, d f=2, P=0.289\right)$. Although malaria cases occurred in all age groups, more malaria cases were observed in children age 5-14 years in Gato $\left(\chi^{2}=14.2, d f=3, P<0.028\right)$. However, there was no statistically significant difference in number of malaria cases between Onota $\left(\chi^{2}=2.9, d f=3\right.$, $P=0.800)$ and Layignaw-Arguba $\left(\chi^{2}=2.3, d f=3\right.$, $P=0.510$ ) among the age groups (Table 5).

\section{Seasonal pattern of malaria cases}

There was a slight difference in malaria transmission pattern in the three study villages at different altitudinal transects. Overall in Layignaw-Arguba, an increased number of malaria cases were observed in August, December and March. In Onota more malaria cases occurred in November. More mixed infections of $P$. falciparum and $P$. vivax were reported in Gato where microscope and RDT were routinely used for malaria parasite detection. August-September 2015 and January-April 2016 were the main malaria transmission seasons in Gato (Fig. 3). 

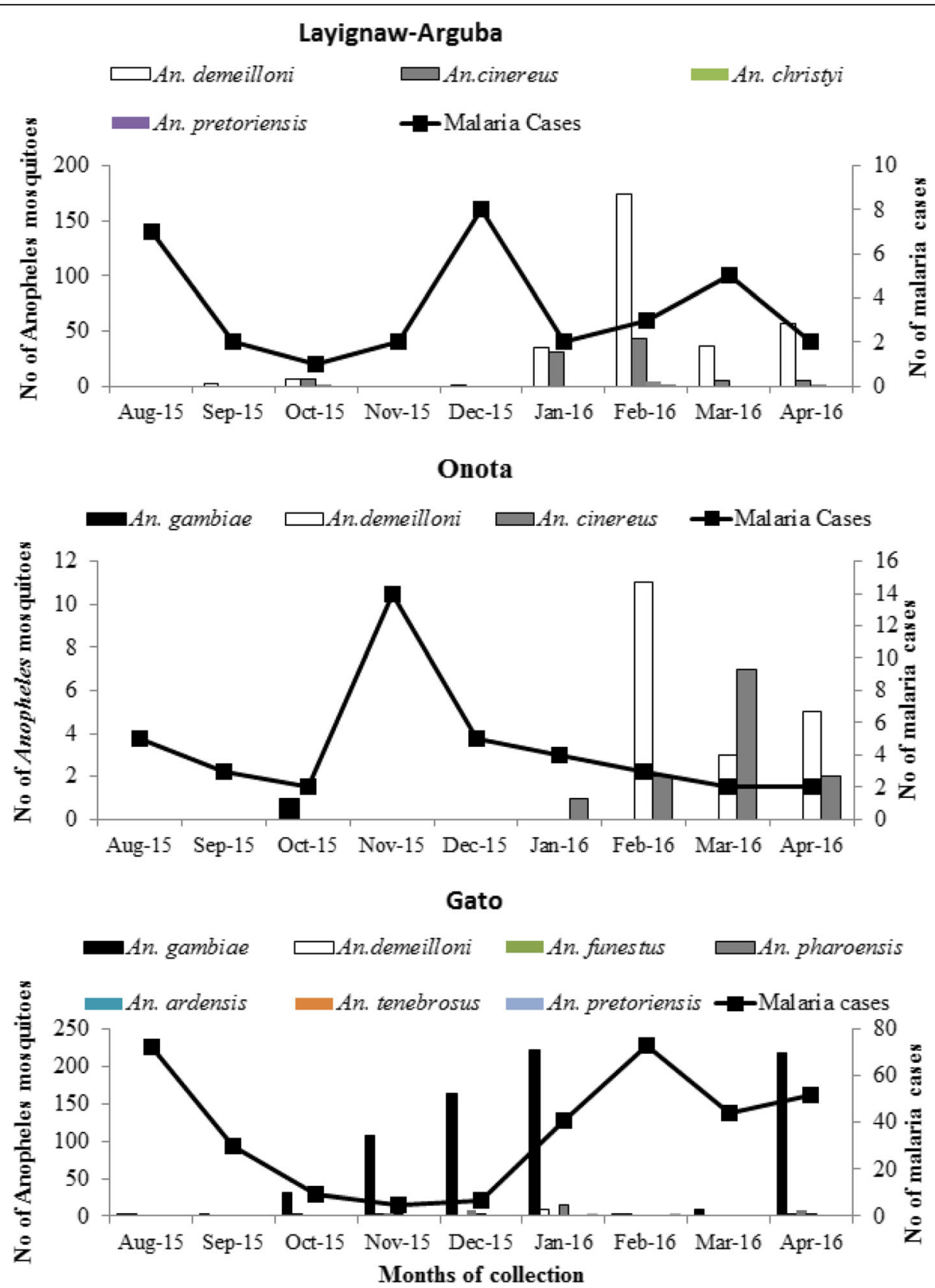

Fig. 2 Monthly catches of Anopheles mosquitoes and malaria cases trend in the three study villages of Dirashe Woreda, south Ethiopia (August 2015-April 2016)

\section{Bednet ownership and use}

Most of the households (442; 92.7\%) had at least one LLIN. Of these, 160 (36.2\%) had only one LLIN, and 282 (64.8\%) had more than one LLIN, and the mean number was 2.1 LLINs (95\% CI: 2.0-2.2). About half of the LLINs $(211 ; 47.7 \%)$ were $2-3$ years old with a mean age of 2.3 years (95\% CI: $2.2-2.4$ ) (Table 6 ).

In Gato, $212(93.0 \%)$ households owned more than one LLINs, and the rest 16 (7.0\%) had one LLIN, with the mean number of 2.8 LLINs (95\% CI: 2.7-2.9). In
Onota $66(65.3 \%)$ of the households owned more than one LLIN and the remaining 35 (34.7\%) had only one LLIN, with the mean number of 1.8 LLIN (95\% CI: 1.61.9). In Layignaw-Arguba, most households (109; 96.5\%) were provided with only one LLIN (Table 6). Among 442 households, $343(77.6 \%)$ reported that anyone of the family members slept under the net the night before the survey and in the rest 99 (22.4\%) households, no one slept under the LLINs. More than half $(53.1 \%$; 182 of the 343) of the LLINs users were mothers and children 
Table 2 Abdominal status of female Anopheles mosquitoes in the three study villages of Dirashe Woreda, south Ethiopia (August 2015-April 2016)

\begin{tabular}{lllll}
\hline Village & Abdominal status & $n(\%)$ & $x^{2}$ & $P$-value \\
\hline Gato & Unfed & $499(60.3)$ & 726.2 & $<0.001$ \\
& Freshly-fed & $265(32.0)$ & & \\
& Half-gravid & $47(5.7)$ & & \\
& Gravid & $17(2.1)$ & & \\
Total & & $828(100)$ & & \\
Onota & Unfed & $23(71.9)$ & 22.5 & $<0.001$ \\
& Freshly-fed & $7(21.9)$ & & \\
& Half-gravid & $2(6.2)$ & & \\
& Gravid & $0(0)$ & & \\
Total & & $32(100)$ & & \\
Layignaw-Arguba & Unfed & $199(48.8)$ & 354.5 & $<0.001$ \\
& Freshly-fed & $195(47.8)$ & & \\
& Half-gravid & $12(2.9)$ & & \\
& Gravid & $2(0.5)$ & & \\
Total & & $408(100)$ & & \\
\hline
\end{tabular}

under five years, and 121 (35.3\%) were all family members. Most of the LLINs 334 (97.4\%) were found hanging in the houses, and 324 (94.5\%) were in good conditions (with no holes and physical damages).

There was a difference in LLINs ownership and usage at different altitudes. The overall LLIN usage was significantly higher in Gato (86.4\%) compared to $71.3 \%$ in Onota and 64.6\% in Layignaw-Arguba $\left(\chi^{2}=23.8, d f=2\right.$, $P<0.001)$.

\section{Indoor residual spray}

In Gato, IRS was done at the end of August and beginning of September 2015 to control malaria vectors. Of 233 surveyed houses, 150 (64.4\%) were sprayed with propoxur $50 \%$ water-dispersible powder with the residual efficacy of 3-6 months at $2 \mathrm{~g} / \mathrm{m}^{2}$. About $35.6 \%$ households were not sprayed. The walls of eight (5.3\%) households were re-plastered after the spray. IRS was conducted when the density of An. arabiensis was very low, and malaria cases have already been built-up in the population (Fig. 4).

\section{Discussion}

There was variation in species composition and infection rate of Anopheles mosquitoes at different altitudinal transects of Dirashe Woreda. Anopheles arabiensis, An. demeilloni, An. cinereus, An. pharoensis, An. funestus-group, An. pretoriensis, An. christyi, An. ardensis and An. tenebrosus were documented in the villages. Anopheles arabiensis was the dominant and the principal malaria vector in lowland Gato as reported in Chano Mille, south Ethiopia [18], whereas in the highland Layignaw-Arguba An. demeilloni was dominant and positive for $P$. falciparum CSPs. The estimated P. falciparum EIR of An. arabiensis was 8.6 infective bites per person/nine months from Gato. Malaria cases were identified in all age groups in the three villages; however, more malaria cases were documented in children age 5-14 years in Gato. Plasmodium falciparum was the dominant parasite species in Gato, whereas in LayignawArguba P. vivax was dominant species.

This study has several strengths and limitations. The entomological and epidemiological data were used to assess malaria transmission patterns at different altitudinal transects. The limitation of the study was the use of secondary data from health facilities. The identification of Anopheles mosquito was based on the morphological characteristics which may result in misclassification as we did not use polymerase chain reaction (PCR) because of the limitation of resources and accesses.

The density of Anopheles mosquito was higher in Gato than Onota and Layignaw-Arguba. This finding agreed with the previous study done in the district [13]. Anopheles demeilloni was the dominant species next to $A n$. christyi in Western Kenya highlands [19]. Anopheles cinereus was the second most common species in Layignaw-Arguba and Onota as it was previously documented in the highlands $[3,13]$. So far these two species were not incriminated as malaria vectors in Ethiopia. However, P. falciparum CSP protein-positive An. cinereus was reported in Eritrea [20]. Anopheles christyi was reported from highland, and it was the second common species next to An. arabiensis elsewhere in Ethiopia [12].

Table 3 Plasmodium falciparum circum-sporozoite protein (CSP) rates of An. arabiensis and An. demeilloni in the three study villages of Dirashe Woreda, south Ethiopia (August 2015-April 2016)

\begin{tabular}{|c|c|c|c|c|c|c|}
\hline \multirow[t]{2}{*}{ Villages } & \multicolumn{2}{|c|}{ An. arabiensis } & \multicolumn{2}{|c|}{ An. demeilloni } & \multicolumn{2}{|l|}{ Overall } \\
\hline & No. tested & Pf CSP positive $(\% ; 95 \% \mathrm{CI})$ & No. tested & Pf CSP positive $(\% ; 95 \% \mathrm{CI})$ & No. tested & Pf CSP positive $(\% ; 95 \% \mathrm{Cl})$ \\
\hline Gato & 754 & $3(0.4 ; 0.08-1.15)$ & 17 & 0 & 771 & $3(0.39 ; 0.08-1.10)$ \\
\hline Onota & 1 & 0 & 19 & 0 & 20 & 0 \\
\hline Layignaw-Arguba & 0 & 0 & 311 & $2(0.64 ; 0.08-2.30)$ & 311 & $2(0.64 ; 0.08-2.30)$ \\
\hline Total & 755 & $3(0.4 ; 0.08-1.15)$ & 347 & $2(0.57 ; 0.05-2.10)$ & 1102 & $5(0.45 ; 0.06-1.10)$ \\
\hline
\end{tabular}

Abbreviations: Pf Plasmodium falciparum, $\mathrm{Cl}$ confidence interval 
Table 4 Monthly CSP rates and EIR of An. arabiensis and the CSP rate of An. demeilloni in the study villages in Dirashe Woreda, south Ethiopia (August 2015-April 2016)

\begin{tabular}{|c|c|c|c|c|c|c|c|}
\hline \multirow[t]{2}{*}{ Study month } & \multirow{2}{*}{$\begin{array}{l}\text { Total Anopheles } \\
\text { collected }\end{array}$} & \multicolumn{4}{|c|}{ An. arabiensis } & \multicolumn{2}{|c|}{ An. demeilloni } \\
\hline & & No. tested & CSP positive $n(\%)$ & $P f E I R^{a}$ & PfEIR ${ }^{b}(95 \%$ CI) & No. tested & CSP positive $n(\%)$ \\
\hline August 2015 & 5 & 2 & 0 & 0 & 0 & 1 & 0 \\
\hline September 2015 & 3 & 1 & 0 & 0 & 0 & 2 & 0 \\
\hline October 2015 & 48 & 32 & $1(3.1)$ & 2.95 & $2.95(0.1-15.0)$ & 8 & 0 \\
\hline November 2015 & 116 & 107 & 0 & 0 & 0 & 3 & 0 \\
\hline December 2015 & 178 & 164 & 0 & 0 & 0 & 1 & 0 \\
\hline January 2016 & 318 & 221 & $2(0.9)$ & 5.9 & $5.9(0.7-19.0)$ & 44 & 0 \\
\hline February 2016 & 242 & 2 & 0 & 0 & 0 & 186 & $2(1.1)$ \\
\hline March 2016 & 61 & 8 & 0 & 0 & 0 & 39 & 0 \\
\hline April 2016 & 297 & 0 & 0 & 0 & 0 & 63 & 0 \\
\hline Totals & 1268 & 755 & $3(0.4)$ & 8.6 & $8.6(1.7-25.0)$ & 347 & $2(0.57)$ \\
\hline
\end{tabular}

${ }^{a}$ Standard method: 1.91(No. ELISA positive from CDC light trap/No. ELISA tested) $\times($ No. An. arabiensis collected from CDC light trap/No. of catches) $\times$ No. days in a month

${ }^{b}$ Alternative method: 1.91 (No. ELISA positive/No. catches) $\times$ No. days in month

Abbreviations: SR sporozoite rate, Pf EIR nine months Plasmodium falciparum entomological inoculation rate, CSP circum-sporozoite protein, CI confidence interval

The human-biting behaviour of An. christyi was reported from Akaki, in Ethiopia [3]. The study in south-central Ethiopia also identified high human blood index of An. christyi, An. demeilloni and An. cinereus [21]. Most Anopheles mosquitoes were collected in the dry season; it may be due to drying of streams and formation of small water bodies which provide suitable breading habitats for Anopheles mosquitoes. Similar results have been reported from highland of South-central Ethiopia [22].

Table 5 Plasmodium species and malaria morbidity among age groups in the three study villages of Dirashe Woreda (August 2015-April 2016)

\begin{tabular}{|c|c|c|c|c|c|c|c|c|}
\hline Village & Age category & Tested & $\begin{array}{l}\text { Positive } \\
n(\%)\end{array}$ & $\begin{array}{l}P f \\
n(\%)\end{array}$ & $\begin{array}{l}P V \\
n(\%)\end{array}$ & $\begin{array}{l}\text { Mixed } \\
n(\%)\end{array}$ & $x^{2}$ & $P$-value \\
\hline \multirow[t]{5}{*}{ Gato } & $<1$ year & 215 & $8(3.7)$ & $1(12.5)$ & $2(25.0)$ & $5(62.5)$ & & \\
\hline & $1-4$ years & 460 & $45(9.8)$ & $12(26.7)$ & $4(8.9)$ & $29(64.4)$ & & \\
\hline & 5-14 years & 408 & $117(28.7)$ & $26(22.2)$ & $13(11.1)$ & $78(66.7)$ & 14.2 & 0.030 \\
\hline & $>15$ years & 751 & $163(21.7)$ & 64 (39.3) & $21(12.9)$ & 78 (47.8) & & \\
\hline & Total & 1834 & $333(18.0)$ & $103(31)$ & $40(12.0)$ & $190(57)$ & & \\
\hline \multirow[t]{5}{*}{ Onota } & $<1$ year & 10 & $1(10.0)$ & $1(100)$ & 0 & 0 & & \\
\hline & $1-4$ years & 29 & $4(13.8)$ & $3(75.0)$ & $1(25.0)$ & 0 & & \\
\hline & 5-14 years & 38 & $7(18.4)$ & $3(42.9)$ & $4(57.1)$ & 0 & 2.9 & 0.800 \\
\hline & $>15$ years & 113 & $28(24.8)$ & $16(57.2)$ & $10(35.7)$ & $2(7.1)$ & & \\
\hline & Total & 190 & $40(21.0)$ & $23(57.5)$ & $15(37.5)$ & $2(5.0)$ & & \\
\hline \multirow[t]{5}{*}{ Layignaw-Arguba } & $<1$ year & 6 & $1(16.7)$ & 0 & $1(100)$ & 0 & & \\
\hline & $1-4$ years & 34 & $2(5.9)$ & 0 & $2(100)$ & 0 & & \\
\hline & 5-14 years & 60 & $5(8.3)$ & $2(40)$ & $3(60)$ & 0 & 2.3 & 0.510 \\
\hline & $>15$ years & 116 & $24(20.7)$ & $11(45.8)$ & $13(54.2)$ & 0 & & \\
\hline & Total & 216 & $32(15)$ & $13(40.6)$ & $19(59.4)$ & 0 & & \\
\hline \multirow[t]{5}{*}{ Overall total } & $<1$ year & 231 & $10(4.3)$ & $2(20.0)$ & $3(30.0)$ & $5(50)$ & & \\
\hline & $1-4$ years & 523 & $51(9.8)$ & $15(29.4)$ & $7(13.7)$ & 29 (56.9) & & \\
\hline & 5-14 years & 506 & $129(25.5)$ & $31(24.0)$ & $20(15.5)$ & $78(60.5)$ & 21.7 & 0.001 \\
\hline & $>15$ years & 980 & $215(22.0)$ & $91(42.3)$ & $44(20.5)$ & $80(37.2)$ & & \\
\hline & Total & 2240 & 405 (18.0) & 139 (34.3) & $74(18.3)$ & $192(47.4)$ & & \\
\hline
\end{tabular}



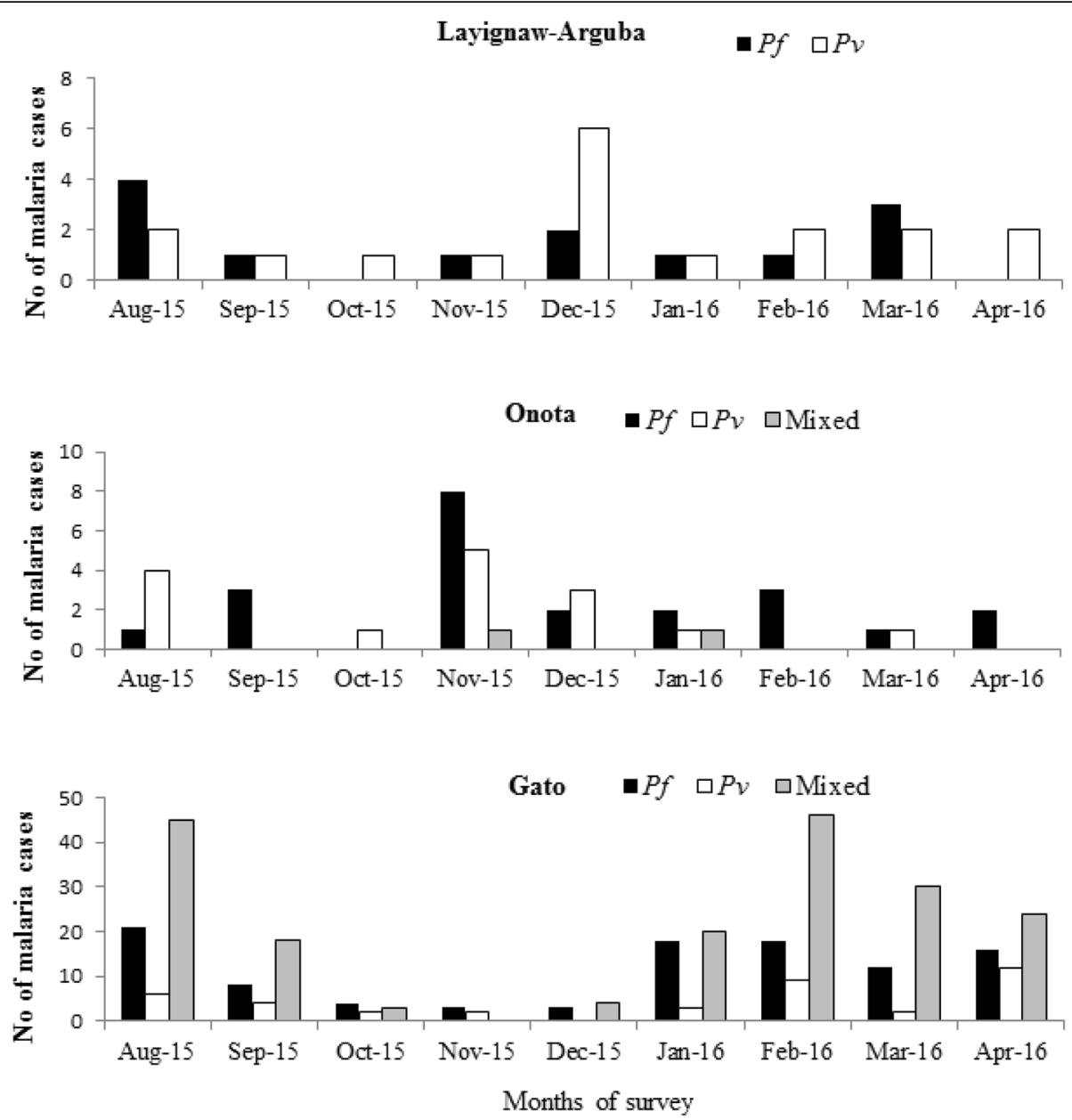

Fig. 3 Monthly malaria cases trend in the three study villages of Dirashe Woreda, south Ethiopia (August 2015-April 2016)

Anopheles arabiensis from Gato and An. demeilloni from Layignaw-Arguba were positive for $P$. falciparum CSPs. The sporozoite rate of An. arabiensis for P. falciparum in Gato was $0.4 \%$, which is similar to $0.32 \%$ from Chano-Mille in southern Ethiopia [23] and 0.3\% in the south-central Ethiopia [21]. The P. falciparum CSP rate of An. demeilloni in Layignaw-Arguba was $0.64 \%$. In Western Kenya, a species morphologically identified as the member of $A n$. demeilloni group was positive for P. falciparum CSPs by ELISA and PCR [24]. Anopheles demeilloni has received attention because it was relatively abundant and its infectivity rate was similar to An. funestus group in western Kenya [24, 25]. The same species was also incriminated in Zambia, which suggests that the distribution of the species may be of regional rather than local importance in malaria transmission [26]. This is the first report in Ethiopia, and so far, no study has reported sporozoite rate of An. demeilloni for comparison. However, confirmation using a more sensitive method such as PCR may be advisable.
The estimated P. falciparum EIR of An. arabiensis was 8.6 infectious bites per person/nine months that were higher than expected for malaria interruption $(<1$ infective bites per person per year) [27]. The nine months EIR of An. arabiensis was higher than the annual EIR of 3.66 infective bites per person per year from central highlands of southern Ethiopia [21]. However, it may be difficult to compare with the findings of a study in south-western Ethiopia which was 17.1 infective bites per person per year [23] since the EIR estimations of the current study were for nine months. The EIR of 8.6 in Gato is enough to sustain malaria transmission in the area, and hence the malaria control interventions should be strengthened to reduce the transmission and for future malaria elimination.

In the current study, more malaria cases were documented in the lowland Gato. It could be due to the existence of an efficient malaria vector An. arbiensis and the warmer climate [28]. Moreover, P. falciparum was the dominant malaria parasites in Gato. On the other hand, P. vivax was the predominant parasite in the highland 
Table 6 Bed net ownership and use in the three study villages of Dirashe Woreda, south Ethiopia (August/September 2015)

\begin{tabular}{|c|c|c|c|c|}
\hline \multirow[t]{2}{*}{ Variable / Village } & Gato $(N=233)$ & Onota $(N=108)$ & Layignaw-Arguba $(N=136)$ & Total $(N=477)$ \\
\hline & $n(\%)$ & $n(\%)$ & $n(\%)$ & $n(\%)$ \\
\hline \multicolumn{5}{|l|}{ Bed net ownership } \\
\hline Yes & $228(97.9)$ & $101(93.5)$ & $113(83.1)$ & $442(92.7)$ \\
\hline No & $5(2.1)$ & $7(6.5)$ & $23(16.9)$ & $35(7.3)$ \\
\hline \multicolumn{5}{|l|}{ Number of LLINs per HH } \\
\hline 1 net & $16(7.0)$ & $35(34.7)$ & $109(96.5)$ & $160(36.2)$ \\
\hline 2 nets & $89(39.0)$ & $57(56.4)$ & $4(3.5)$ & $150(33.9)$ \\
\hline 3 nets & $65(28.5)$ & $8(7.9)$ & $0(0)$ & $73(16.5)$ \\
\hline 4 and more nets & $58(25.5)$ & $1(1.0)$ & $0(0)$ & $59(13.4)$ \\
\hline \multicolumn{5}{|l|}{ Source of bed net } \\
\hline Government & $228(100)$ & $101(100)$ & $109(96.5)$ & $438(99.1)$ \\
\hline Self-purchased & $0(0)$ & $0(0)$ & $4(3.5)$ & $4(0.9)$ \\
\hline \multicolumn{5}{|l|}{ Age of bed net } \\
\hline$<1$ years & $2(0.9)$ & $79(78.2)$ & $41(36.3)$ & $122(27.6)$ \\
\hline $1-2$ years & $31(13.6)$ & $18(17.8)$ & 38 (33.6) & $87(19.7)$ \\
\hline $2-3$ years & $195(85.5)$ & $4(4.0)$ & $12(10.6)$ & $211(47.7)$ \\
\hline$>3$ years & $0(0)$ & $0(0)$ & $22(19.5)$ & $22(5.0)$ \\
\hline \multicolumn{5}{|c|}{ Any one slept under the bed net last night? } \\
\hline Yes & $198(86.8)$ & $72(71.3)$ & $73(64.6)$ & $343(77.6)$ \\
\hline No & $30(13.2)$ & $29(28.7)$ & $40(35.4)$ & $99(22.4)$ \\
\hline \multicolumn{5}{|l|}{ Who slept under the bed net? } \\
\hline Whole family & $91(46.0)$ & $28(38.9)$ & $2(2.7)$ & $121(35.3)$ \\
\hline$<5$ years (children only) & $8(4.0)$ & $2(2.8)$ & $10(13.7)$ & $20(5.8)$ \\
\hline Mother and children $<5$ years & $93(47.0)$ & $39(54.2)$ & $50(68.5)$ & $182(53.1)$ \\
\hline Father and mother only & $6(3.0)$ & $3(4.1)$ & $11(15.1)$ & $20(5.8)$ \\
\hline \multicolumn{5}{|l|}{ Bed net hanged } \\
\hline Yes & $193(97.5)$ & $72(100)$ & $69(94.5)$ & $334(97.4)$ \\
\hline No & $5(2.5)$ & $0(0)$ & $4(5.5)$ & $9(2.6)$ \\
\hline \multicolumn{5}{|l|}{ Bed net condition } \\
\hline In good condition (no holes) & $197(99.5)$ & $70(97.2)$ & $57(78.1)$ & $324(94.5)$ \\
\hline Holed & $1(0.5)$ & $2(2.8)$ & $7(9.6)$ & $10(2.9)$ \\
\hline Worn out/not in use & $0(0)$ & $0(0)$ & $9(12.3)$ & $9(2.6)$ \\
\hline
\end{tabular}

Abbreviations: $H H$ household, LLIN long lasting insecticidal net

Layignaw-Arguba, as reported by other studies in Ethiopia [9, 12]. It may be due to the characteristic of $P$. vivax which can develop in the vectors at a low temperature and can survive at high altitude and cool climate [29, 30]. We also documented more malaria cases in the age group 5-14 years in Gato as reported by other studies in Ethiopia [31-33]. The scenario was different in Onota and Layignaw-Arguba where more malaria cases (though not significantly different) was observed in the age groups $>15$ years. It could be because of the movement of people from highland to the lowland for farming and stay there sometimes and may acquire malaria parasites. When the travellers go back to homes in the highlands, they can serve as a source of infection and may result in a local malaria transmission [34].

Malaria in Layignaw-Arguba could be either indigenous, imported or both. The detection of malaria in age group $<1$ year who are less likely to travel to lowland and incrimination of $A n$. demeilloni may imply the indigenous malaria transmission. Similarly, highlands of Ethiopia ranging from an altitude of 1500-2500 masl have experienced malaria epidemics [11]. There is also an increase in stability of malaria in highland fringes of East Africa [5, 35]. The causes for changing malaria epidemiology may be the changing climatic and ecological variables [6]. The increasing temperature can increase 

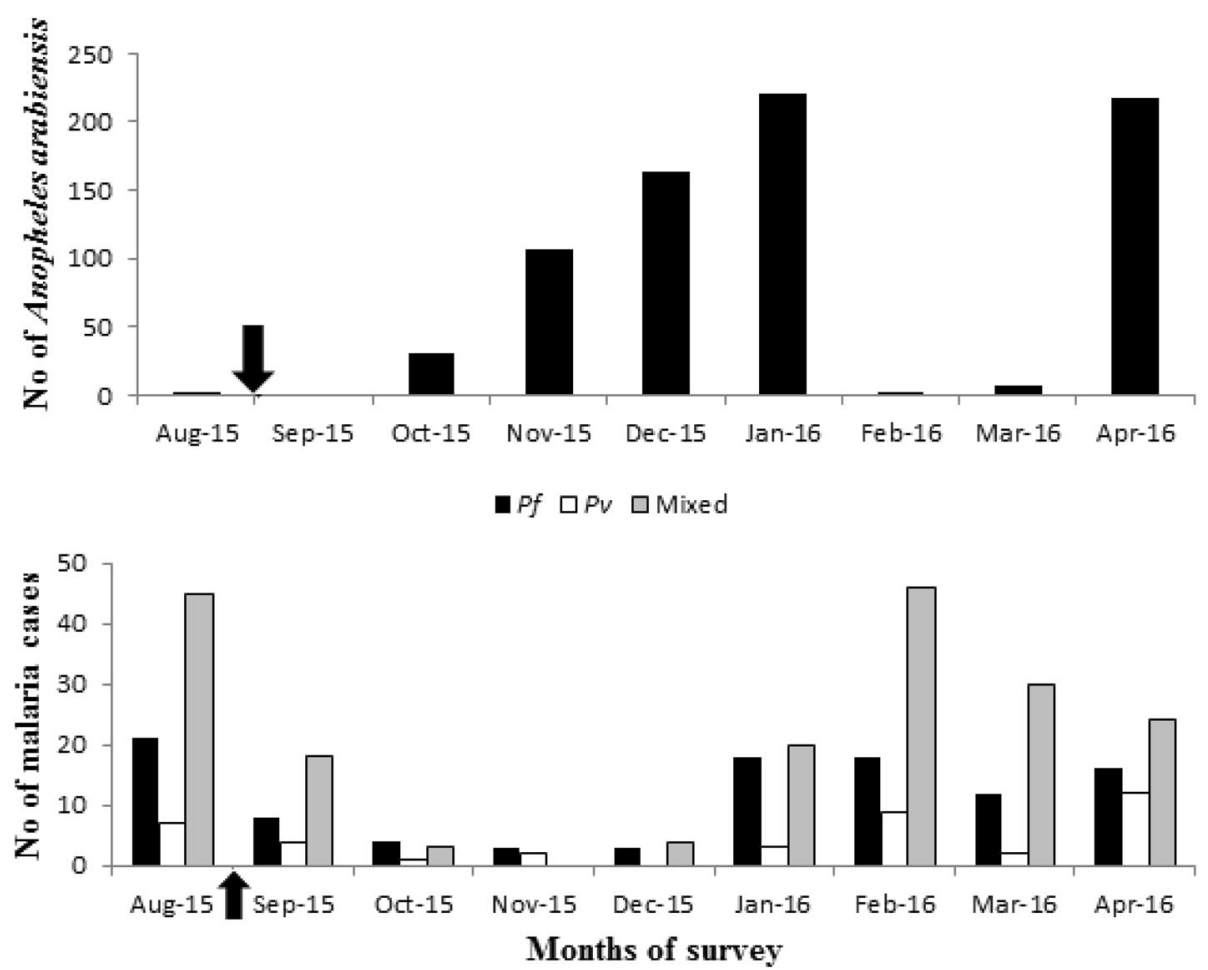

Fig. 4 Monthly An. arabiensis density, malaria cases and IRS introduction time during the study period in Gato in Dirashe Woreda, south Ethiopia (August 2015-April 2016). The arrows indicate the time of indoor residual spraying

the digestion of blood meals taken by the mosquitoes which in turn increase human biting frequency [36] and shortens the development time of malaria parasite within the mosquito vector [6]. However, the origin of malaria at highland could be further investigated by a prospective study.

The current study revealed that $93 \%$ of the households owned at least one LLIN and $64 \%$ of the households owned more than one LLIN which is much higher than the report of Ethiopian malaria indicator survey of 2011 [37]. Despite the high ownership and utilisation of LLINs in the lowland Gato, malaria is endemic and continued as public health problem. This may be due to a shift in peak biting behaviour of $A n$. arabiensis to early evening before people go to bed or the vector feeding outdoors [38]. Moreover, the percentage of children under five years in Gato who sleep under the LLINs the night preceding the survey was $51 \%$ only. This finding was lower than the report of the Ethiopia malaria indicator survey of 2011 which was $64.5 \%$ at national level, $66.1 \%$ in Southern Nations Nationalities and People's Region state (SNNPRs) [37] and 62\% in Chano Mille, south Ethiopia [39].

The percentage of households protected by IRS in Gato (IRS was applicable only in this village) was $64.4 \%$ which is lower than $80 \%$; the recommended coverage for effective use of IRS at the community level [27]. This finding was, however, higher than the report of 2011
MIS which was $46.6 \%$ at the national level and $58.6 \%$ in SNNPRs [37]. However, the number of indoor Anopheles mosquitoes during the house spray was low. On the other hand, one month after the spray from October through January the number of indoor Anopheles mosquitoes was increased. This suggests that the residual efficacy of propoxur may be less than the expected duration or the sprayer may use doses less than the recommended. It may not be due to the resistance of An. arabiensis because they are susceptible to propoxur in most parts of the country [40]. Moreover, the spray was conducted when the number of malaria cases increased. This suggests that the spray period may not be designed based on the density of local malaria vector and malaria transmission patterns, and hence is less likely to be effective. Therefore, the policy of when to spray may need revision based on the local evidence for the effective use of IRS.

\section{Conclusions}

There was variation in species composition and infection rate of Anopheles mosquitoes at different altitudinal transects. Anopheles arabiensis was the most dominant and the principal vector of malaria in Gato with an estimated P. falciparum EIR of 8.6 infective bites/ person/ nine months. On the other hand, An. demeilloni was the predominant and positive for $P$. falciparum CSPs in 
Layignaw-Arguba. The incrimination of Plasmodiumpositive Anopheles and presence of malaria in children under five years in Layignaw-Arguba may justify the risk of local malaria transmission in the highland of Dirashe Woreda, south Ethiopia. Hence, malaria control intervention strategies could include the highland village of the district. However, there is a need for further investigation and confirmation using more sensitive molecular techniques to consider $A n$. demeilloni as a proven vector of malaria in Ethiopia.

\section{Abbreviations}

CDC: Centres for Disease Control and Prevention; CSPs: Circum-sporozoite proteins; EIR: Entomologic inoculation rate; ELISA: Enzyme-linked immunosorbent assay; IRS: Indoor residual spraying; LLIN: Long-lasting insecticidal net; RDT: Rapid diagnostic test

\section{Acknowledgements}

Dirashe Woreda Health Office, Agricultural Office, the Health Centers of Gato and Gidole, the health posts of Layignaw-Arguba, Onota, Gallo and Gato are acknowledged for providing useful and supporting information. We acknowledge Yohannes Negash from Aklilu Lemma Institute of Pathobiology for giving training on ELISA and analysing mosquitoes for Plasmodium CSPs. Nigatu Eligo and Gemechu Leta of Arba Minch University are acknowledged for their assistance in Plasmodium CSPs analysis. Mr. Geletu Legesse is highly acknowledged for his generous and unlimited support in field work especially in Gato.

\section{Funding}

Norwegian Programme for Capacity Development in Higher Education and Research for Development (NORHED) is highly acknowledged for funding this study. The funding body played no role in study design, field data collection, data analysis and interpretation, and reporting.

\section{Availability of data and materials}

The data supporting the conclusions of this article are included within the article.

\section{Authors' contributions}

TYD: study design, conducted data collection and laboratory mosquito analysis, data analysis and, wrote the first draft of the manuscript; FM: study design, field supervision, mosquito analysis in the laboratory, and manuscript revision; BL: study design, field supervision and manuscript revision. All authors read and approved the final manuscript.

\section{Ethics approval and consent to participate}

The ethical approval was obtained from the Ethical Review Committee of Ethiopia Public Health Institute (SERO-042-12-2015). The objective of the study was discussed with the district administration and health office to obtain approval letter for each study locality. In the same way, the discussion was also made with the village administrators. Informed consent was obtained from the head of the selected households.

\section{Consent for publication}

Not applicable.

\section{Competing interests}

The authors declare that they have no competing interests.

\section{Publisher's Note}

Springer Nature remains neutral with regard to jurisdictional claims in published maps and institutional affiliations.

\section{Author details}

'Department of Biology, Arba Minch University, Arba Minch, Ethiopia. ${ }^{2}$ Dirashe Woreda Health Office, Malaria and Other Vector-Borne Diseases Control Unit, Gidole, Ethiopia. ${ }^{3}$ Centre for International Health, University of Bergen, Bergen, Norway.
Received: 12 December 2016 Accepted: 13 July 2017

Published online: 19 July 2017

\section{References}

1. Gething P, Casey DC, Weiss DJ, Bisanzio D, Bhatt S, Cameron E, et al. Mapping Plasmodium falciparum mortality in Africa between 1990 and 2015. N Engl J Med. 2016. doi:10.1056/NEJMoa1606701.

2. Adhanom T, Deressa W, Witten KH, Getachew A, Seboxa T. Malaria. In: Berhane $\mathrm{Y}$, Haile-Mariam D, Kloos H, editors. Epidemiology and ecology of health and disease in Ethiopia. Addis Ababa: Shama Books; 2006.

3. Woyessa A, Gebre-Micheal T, Ali A. An indigenous malaria transmission in the outskirts of Addis Ababa, Akaki town and its environs. Ethiop J Health Dev. 2004:18:1-7.

4. Graves PM, Richards FO, Ngondi J, Emerson PM, Shargie EB, Endeshaw T, et al. Individual, household and environmental risk factors for malaria infection in Amhara. Oromia and SNNP regions of Ethiopia Trans R Soc Trop Med Hyg. 2009;10:1016.

5. Siraj A, Santos-Vega M, Bouma MJ, Yadeta D, Carrascal DR, Pascual M. Altitudinal changes in malaria incidence in highlands of Ethiopia and Colombia. Science. 2014:343:1154.

6. Githeko A, Lindsay SW, Confalonieri UE, Patz JA. Climate change and vectorborne diseases: a regional analysis. Bull World Health Organ. 2000;78:1136-47.

7. Minakawa N, Omukunda E, Zhou G, Githeko A, Yan A. Malaria vector productivity in relation to the highland environment in Kenya. Am J Trop Med Hyg. 2006:75:448-53.

8. Lindsay S, Martens WJ. Malaria in the African highlands: past, present and future. Bull World Health Organ. 1998;76:33-45.

9. Woyessa A, Deressa W, Ali A, Lindtjørn B. Prevalence of malaria infection in Butajira area, south-central Ethiopia. Malar J. 2012;11:84.

10. Alemum K, Worku A, Berhane Y, Kumie A. Men traveling away from home are more likely to bring malaria into high altitude villages, northwest Ethiopia. PLoS One. 2014;9:e95341.

11. Fontaine R, Najjar AE, Prince JS. The 1958 malaria epidemic in Ethiopia. Am J Trop Med Hyg. 1961;10:795-803.

12. Tesfaye S, Belyhun Y, Teklu T, Mengesha T, Petros B. Malaria prevalence pattern observed in the highland fringe of Butajira, southern Ethiopia: A longitudinal study from parasitological and entomological survey. Malar J. 2011;10:153.

13. Gone T, Balkew M, Gebre-Michael T. Comparative entomological study on ecology and behaviour of Anopheles mosquitoes in highland and lowland localities of Derashe District, southern Ethiopia. Parasit Vectors. 2014;7:483.

14. Lines J, Curtis CF, Wilkes TJ, Njunwa KJ. Monitoring human-biting mosquitoes (Diptera: Culicidae) in Tanzania with light-traps hung beside mosquito nets. Bull Entomol Res. 1991;81:77-84.

15. Gillies M, Coetzee M. A supplement to the Anophelinae of Africa south of the Sahara. S Afr Inst Med Res. 1987;55:143.

16. Wirtz R, Burkot T, Graves P, Andre R. Field evaluation of enzymelinked immunosorbent assays for $P$. falciparum and $P$. vivax sporozoites in mosquitoes (Diptera: Culicidae) from Papua, new Guinea. J Med Entomol. 1987;24:433-7

17. Fornadel C, Norris LC, Norris DE. Centres for disease control light traps for monitoring Anopheles arabiensis human biting rates in an area with low vector density and high insecticide-treated bed net use. Am J Trop Med Hyg. 2010;83:838-42.

18. Massebo F, Balkew M, Gebre-Michael T, Lindtjorn B. Blood meal origins and insecticide susceptibility of Anopheles arabiensis from Chano in south-West Ethiopia. Parasit Vectors. 2013;6:44.

19. Mulambalah C, Siamba DN, Ngeiywa MM, Vulule JM. Anopheles species distribution and breeding habitat distribution and prospect for focused malaria control in the westerin highland of Kenya. Int J Trop Med. 2011;6:44-51

20. Shililu J, Ghebremeskel T, Mengistu S, Fekadu H, Zerom M, Mbogo C, et al. Distribution of anopheline mosquitoes in Eritrea. Am J Trop Med Hyg. 2003; 69:295-302

21. Animut A, Balkew M, Gebre-Michael T, Lindtjørn B. Blood meal sources and entomological inoculation rates of anophelines along a highland altitudinal transect in south-central Ethiopia. Malar J. 2013:12:76.

22. Animut A, Gebre-Michael T, Balkew M, Lindtjørn B. Abundance and dynamics of anopheline larvae in a highland malarious area of south-centra Ethiopia. Parasit Vectors. 2012;5:117. 
23. Massebo F, Balkew M, Gebre-Michael T, Lindtjørn B. Entomologic inoculation rates of Anopheles arabiensis in southwestern Ethiopia. Am J Trop Med Hyg. 2013;89:466-73.

24. Conn J. News from Africa: novel anopheline species transmit Plasmodium in western Kenya. Am J Trop Med Hyg. 2016;94:251-2.

25. Ototo E, Mbugi JP, Wanjala CL, Zhou G, Githeko AK, Yan G. Surveillance of malaria vector population density and biting behaviour in western Kenya. Malar J. 2015;14:244.

26. Lobo N, Laurent BS, Sikaala CH, Hamainza B, Chanda J, Chinula D, et al. Unexpected diversity of Anopheles species in eastern Zambia: implications for evaluating vector behavior and interventions using molecular tools. Sci Rep. 2015;5:17952.

27. Shaukat A, Breman JG, McKenzie FE. Using the entomological inoculation rate to assess the impact of vector control on malaria parasite transmission and elimination. Malar J. 2010:9:122.

28. Gething P, Van Boeckel TP, Smith DL, Guerra CA, Patil AP, Snow RW, Hay SI. Modelling the global constraints of temperature on transmission of Plasmodium falciparum and P. vivax. Parasit Vectors. 2011;4:92.

29. Gething P, Elyazar IRF, Moyes CL, Smith DL, Battle KE, Guerra CA, et al. A long neglected world malaria map: Plasmodium vivax endemicity in 2010. PLoS Negl Trop Dis. 2012;6:e1814.

30. Stevenson J, Pinchoff J, Muleba M, Lupiya J, Chilusu H4, Mwelwa I, et al. Spatio-temporal heterogeneity of malaria vectors in northern Zambia: implications for vector control. Parasit Vectors. 2016;9:510.

31. Peterson I, Borrell LN, El-Sadr W, Teklehaimanot A. Individual and household level factors associated with malaria incidence in a highland region of Ethiopia: a multilevel analysis. Am J Trop Med Hyg. 2009;80:103-11.

32. Woyessa A, Deressa W, Ali A, Lindtjørn B. Malaria risk factors in Butajira area, south-central Ethiopia: a multilevel analysis. Malar J. 2013;12:273.

33. Loha E, Lindtjørn B. Predictors of Plasmodium falciparum malaria incidence in Chano Mille, south Ethiopia: a longitudinal study. Am J Trop Med Hyg. 2012;87:450-9.

34. Lynch C, Roper C. The transit phase of migration: circulation of malaria and its multidrug-resistant forms in Africa. PLoS Med. 2011;8:e1001040.

35. Zhou G, Minakawa N, Githeko AK, Yan G. Association between climate variability and malaria epidemics in the east African highlands. Proc Natl Acad Sci USA. 2004:101:2375-80.

36. Afrane Y, Githeko AK, Yan G. Malaria transmission in the African highlands in a changing climate situation: perspective from Kenyan highlands. In Tech J. 2011;6:54-6.

37. MIS. Ethiopia National Malaria Indicator Survey 2011. The Ethiopian health and nutrition research institute \& partners: Federal Demochratic Republic of Ethiopia Minstry of health. 2012.

38. Yohannes $\mathrm{M}$, Boelee E. Early biting rhythm in the afro-tropical vector of malaria, Anopheles arabiensis, and challenges for its control in Ethiopia. Med Vet Entomol. 2012;26:103-95.

39. Loha E, Tefera K, Lindtjørn B. Freely distributed bed-net use among Chano Mille residents, south Ethiopia: a longitudinal study. Malar J. 2013;12:23.

40. Balkew M, Getachew A, Chibsa S, Olana D, Reithinger R, Brogdon W. Insecticide resistance: a challenge to malaria vector control in Ethiopia. Malar J. 2012;11:139

\section{Submit your next manuscript to BioMed Central and we will help you at every step:}

- We accept pre-submission inquiries

- Our selector tool helps you to find the most relevant journal

- We provide round the clock customer support

- Convenient online submission

- Thorough peer review

- Inclusion in PubMed and all major indexing services

- Maximum visibility for your research

Submit your manuscript at www.biomedcentral.com/submit

CBiomed Central 